\title{
High frequency heart rate variability evoked by repetitive transcranial magnetic stimulation over the medial prefrontal cortex: A preliminary investigation on brain processing of acute stressor-evoked cardiovascular reactivity
}

\author{
Eduardo Manuel Gonçalves $^{1 *}$, Saul Neves de Jesus ${ }^{2,3}$ \\ ${ }^{1}$ Department of Psychiatry and Mental Health of Hospital of Faro, Faro, Portugal \\ ${ }^{2}$ Department of Psychology (Health Psychology), Faculty of Social Sciences, University of Algarve, Faro, Portugal \\ ${ }^{3}$ Research Center for Spatial and Organizational Dynamics of Algarve, Faro, Portugal \\ Email: *eduar.goncalves@,gmail.com
}

Received 21 May 2013; revised 22 June 2013; accepted 30 June 2013

Copyright (C) 2013 Eduardo Manuel Gonçalves, Saul Neves de Jesus. This is an open access article distributed under the Creative Commons Attribution License, which permits unrestricted use, distribution, and reproduction in any medium, provided the original work is properly cited.

\begin{abstract}
Introduction: Transcranial Magnetic Stimulation (TMS) is a non-invasive technique for brain stimulation. Repetitive TMS (rTMS) over the medial Prefrontal Cortex (mPFC), Broadman Area 10 (BA10) may stimulate transynaptically perigenual Anterior Cingulate Cortex (pACC, BA 33), insula, amigdala, hypothalamus and connected branches of the Autonomic Nervous System (ANS) involved in stressorevoked cardiovascular reactivity. Stressors are associated with an increase in sympathetic cardiac control, a decrease in parasympathetic control, or both, and, consequently, an increase in systolic/stroke volume, total vascular impedance/resistance and heart rate, a decrease of baroreflex sensitivity, i.e., an increase in blood pressure/arterial tension. Objectives and Aims: The present work aims, using TMS and accordingly to Gianaros modeling, based on functional neuroimaging studies and previous neuroanatomical data from animal models, to probe the connectivity of brain systems involved in stressor-evoked cardiovascular reactivity and to explore TMS potential as a tool for detection and stratification of individual differences concerning this reactivity and hemorreological risk factors correlated with the development of Coronary Heart Disease (CHD). Methods: Both subjects, a 52 years old male and a 40 years old female with previous increased Low Frequency (LF)/High Frequency (HF) Heart Rate Variability (HRV) ratios
\end{abstract}

*Corresponding author. (respectively, 4.209/3.028) without decompensated cardiorespiratory symptoms, gave informed consent, and ethico-legal issues have been observed. Electroencephalographic (EEG) monitoring has been performed for safety purposes. Immediately after administration, over the mPFC, of 15 pulses of rTMS, during 60 second, with an inductive electrical current, at the stimulating coil, of 85.9 Ampère per $\mu$ second and 66 Ampère per $\mu$ second, respectively, for male and female subjects (a "figure-of-eight" coil and magnetic stimulator MagLite, Dantec/Medtronic, have been used), HRV spectrum analysis (cStress software) has been performed (during 5 minutes, in supine position). Results: In both subjects, LF power, HF power and LF/HF ratio results, before and after rTMS administration, pointed towards sympathetic attenuation and parasympathetic augmentation (respectively, in male/female subject: decreased LF power-65.1 nu/69.3 nu, before rTMS; $56.1 \mathrm{nu} / 41.6$ nu, after rTMS; increased HF power-15.5 nu/22.9 nu, before rTMS; 30.9 nu/45.5 nu, after rTMS). Conclusions: In this preliminary investigation, the existence of a link between "mind" and heart's function has been put in evidence, through a reversible "virtual" lesion, of brain systems involved in cardiovascular control, caused by TMS. Repetitive TMS over mPFC decreased brain function involved in stressorevoked cardiovascular reactivity, suggesting the importance of TMS in the management of stress-related cardiovascular disorders. 
Keywords: Repetitive Transcranial Magnetic Stimulation (rTMS); Medial Prefrontal Cortex (mPFC); Anterior Cingulate Cortex (ACC); Amigdala; Autonomic Nervous System (ANS); Heart's Conducting System; Acute Sressor-Evoked Cardiovascular (Blood Pressure) Reactivity; Heart Rate Variability (HRV)

\section{INTRODUCTION}

\subsection{Acute Sressor-Evoked Cardiovascular Reactivity (Figure 1)}

Through neuroimaging studies, it has been made correlations between brain areas involved in individual blood pressure (cardiovascular) reactivity and Coronary Heart Disease (CHD). Perigenual Anterior Cingulate Cortex (pACC), the affective division of cingulate cortex, is connected to circuits of the orbital and medial Prefrontal Cortex (mPFC), insula, amygdala, hypothalamus, Periaqueductal Gray (PAG), pons, medulla and the (presympathetic) Inter-Medio-Lateral Cell Column of the spinal cord (IMLCC), and it supports stressor-evoked autonomic/cardiovascular reactivity [1-3]. Dorsal Anterior Cingulate Cortex (dACC), the cognitive-motor division of cingulate cortex, is connected to adjacent circuitry of the lateral PFC, motor/supplementary motor cortex and posterior parietal cortex, supports functions related with

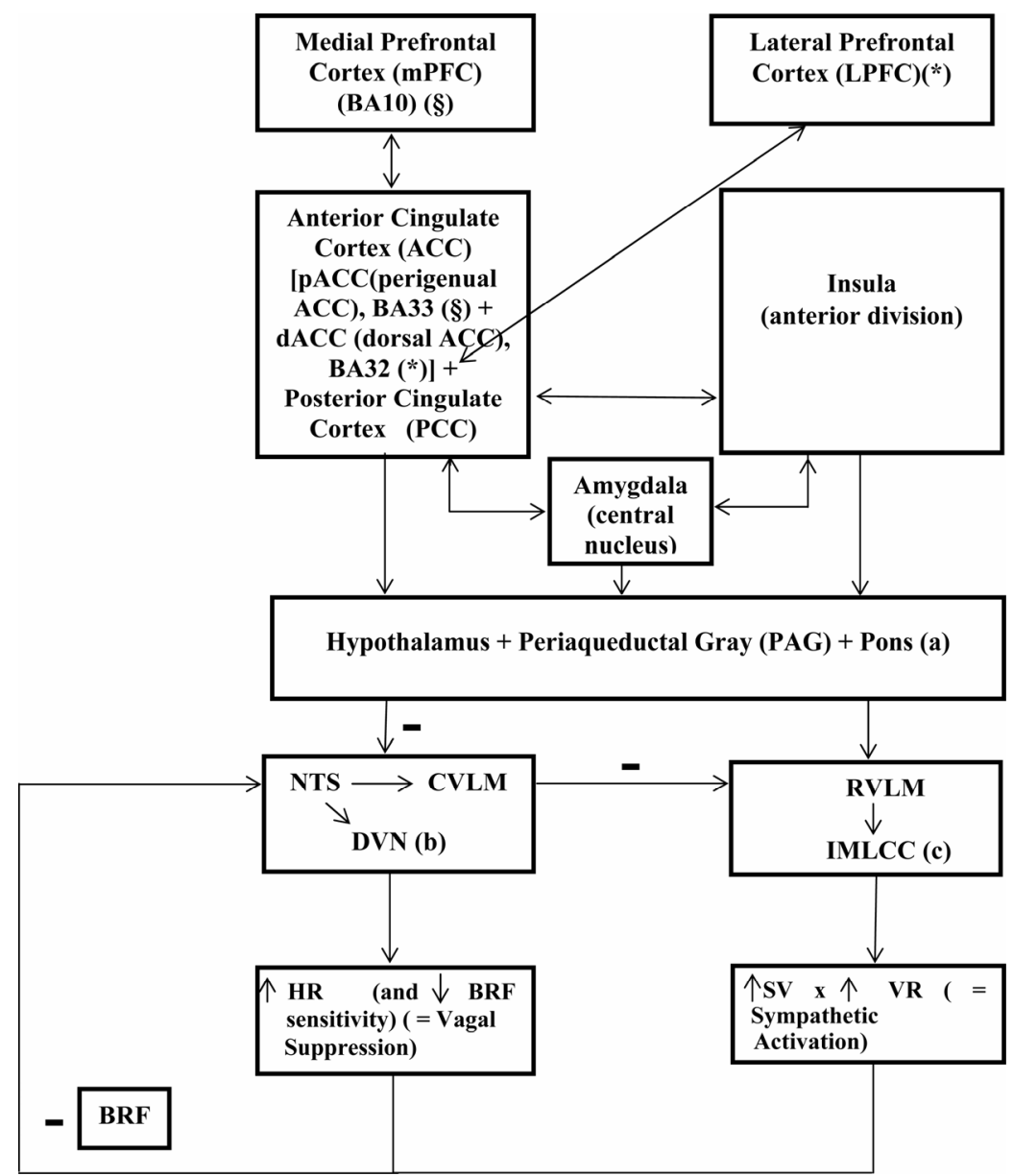

Figure 1. Processing of stressor-related information (stressor-evoked blood pressure/cardiovascular reactivity) by brain systems. Blood Pressure (BP) is a result of a multiplication consisting of three factors: Stroke Volume (SV), Heart Rate (HR) and Total Vascular Resistance (VR) (these factors are increased by stress). Baroreflex Feedback (BRF) and relations between (a), (b) and (c) blocks are inhibitory/negative ( - ) influences; the other relations are excitatory/positive influences. BA, Broadmann Area; NTS, Nucleus Tractus Solitarius; CVLM, Caudal VentroLateral Medulla; DVN, Dorsal Vagal Nucleus; NA, Nucleus Ambiguous; RVLM, Rostral Ventro-Lateral Medullary; IMLCC, Inter-Medio-Lateral Cell Column; §, BA10 connects directly to BA33; *, LPFC connects directly to BA32 (Model adapted from Peter Gianaros, 2008, with Elsevier and author's expressed permissions). 
attention, executive control and conflict and error monitoring [4], and processes emotion-related physiologic reactivity and subjective distress - awareness of subjective emotional experiences [5], pain-related anxiety [6] and intentional regulation of autonomic activity [7]. Posterior Cingulate Cortex (PCC) supports evaluative processes related to cognition and emotion; research of Gianaros et al. revealed that processing of stressors by PCC may indirectly modulate autonomic/cardiovascular reactivity, through connections with pACC and dACC [8]. The insula, particularly the anterior division, presents efferent and afferent connections similar to those of ACC, i.e., with amygdala, hypothalamus, thalamus, PAG, pons, Nucleus Tractus Solitarius (NTS) and medullary and brainstem areas that control pre-autonomic nuclei innervating peripheral target organs $[9,10]$; afferent projections from peripheral target organs provide insula with a "viscerotopic" map of the body [11]. Accordingly to Gianaros and Critchley, insula activation has been associated with stressor-evoked blood pressure reactivity [8, 12-19]. The amygdala is involved in the rapid assignment of emotional salience to environmental events [2023]; its central nucleus sends information concerning behavioral adaptive changes and physiologic adjustments, through the stria terminalis, to lateral and paraventricular hypothalamic nuclei and to PAG, medullary, and preautonomic nuclei; the central nucleus of amygdala is also connected to dACC, pACC and insula [24-26]. The amygdala regulates BP reactivity through its interference with the Baroreflex (BRF). The BRF-a negative feedback control mechanism, for adjustment of Heart Rate (HR), Cardiac Output (CO) and Vascular Resistance (VR), in order to maintain Blood Pressure (BP) within a homeostatic range-relies on afferent projections, from cardiopulmonary mechanoreceptors and chemoreceptors, that signal changes in BP to the NTS: afferent activation of the NTS activates vagal nuclei in the medulla and, through signaling with the Caudal Ventro-Lateral Medulla (CVLM), inhibits pre-sympathetic nuclei in the Rostral Ventro-Lateral-Medulla (RVLM) and IMLCC. The amygdala can gate BRF, through inhibitory projections to the NTS and excitatory projections to the RVLM [27-29]. The ACC and insula can also gate the BRF, on exposure to acute stressors, allowing BP to exceed its regulatory set point $[27,28,30]$. Bernston et al. hypothesized that the amygdala and networked cortical areas may underlie individual cardiovascular reactivity by linking stressor-related processing with BRF suppression [27]. Resting levels of High-Frequency Heart Rate Variability (HF-HRV), an indicator of cardiac parasympathetic activity linked to cardiovascular disease risk, have been associated with PCC BOLD activation to griefrelated stimuli in bereaved individuals $[31,32]$.

\subsection{Transcranial Magnetic Stimulation (TMS) (Figure 2)}

Neuronal stimulation using TMS is achieved via the principles of electromagnetic induction. A stimulating coil is placed over the surface of the scalp, and, when the stimulator unit is discharged, a large current is transferred into the coil, generating a magnetic field, which induces a current within proximate electro-conductive tissues and generates action potentials in cortical neurons. The depth and focality of stimulation is influenced by the size and shape of the stimulating coil: with "figureof-eight" coil, the magnetic field peaks along the intersection of the two windings. Single-pulse TMS, delivered individually (not coupled with another pulse), is used to: measure aspects of cortico-motor excitation and inhibition; map cortical representation; examine central motor encoding and conduction time; create temporary virtual lesions (disrupting cortical activity), useful in cognitive neuroscience studies [33-38]. Repetitive TMS (rTMS) is used to alter neuronal excitability of a specific region of the cortex, influencing cortical plasticity, and their effects depend upon the stimulation parameters applied. Determining stimulation intensity as a percentage of the resting stimulation-evoked motor threshold (the lowest stimulus intensity that gives rise to a $50 \mu \mathrm{V}$ evoked response, in the relaxed target muscle $50 \%$ of the time, following a train of at least 6 stimuli) reduces the effects of individual variability of motor cortex excitability [39-45]. Stimulation's frequency is the most determinant of rTMS effect on cortical excitability. Low-frequency rTMS (1 Hz or less), at motor threshold intensities, suppresses cortical excitability, and the duration of this inhibitory effect is similar to the application's one; high frequency, suprathreshold, stimulation, however, increases cortical excitability, and this period of hyperexcitability may last for minutes [46-50]. In healthy controls and in persons with neuropsychiatric disorders, rTMS can change cortical excitability that lasts beyond the stimulation's period, and these effects may arise through Kindling/Long Term Potentiation (LTP) and Quenching/Long Term Depression (LTD) mechanisms in horizontal intracortical cells; also cortical stimulation propagates to secondarily connected cortical areas). Low-frequency rTMS, due to its resulting suppression of cortical excitability, is a potential treatment for disorders characterized by cortical hyperexcitability (e.g., Tourette's syndrome); high-frequency rTMS is a potential treatment for motor and psychiatric disorders characterized by reduced cortical excitability (e.g., stroke, Parkinson's disease, depressive disorders). A large number of these studies involve stimulation of the left DorsoLateral Prefrontal Cortex (DLPFC), because early rTMS investigations suggested a relationship between major 

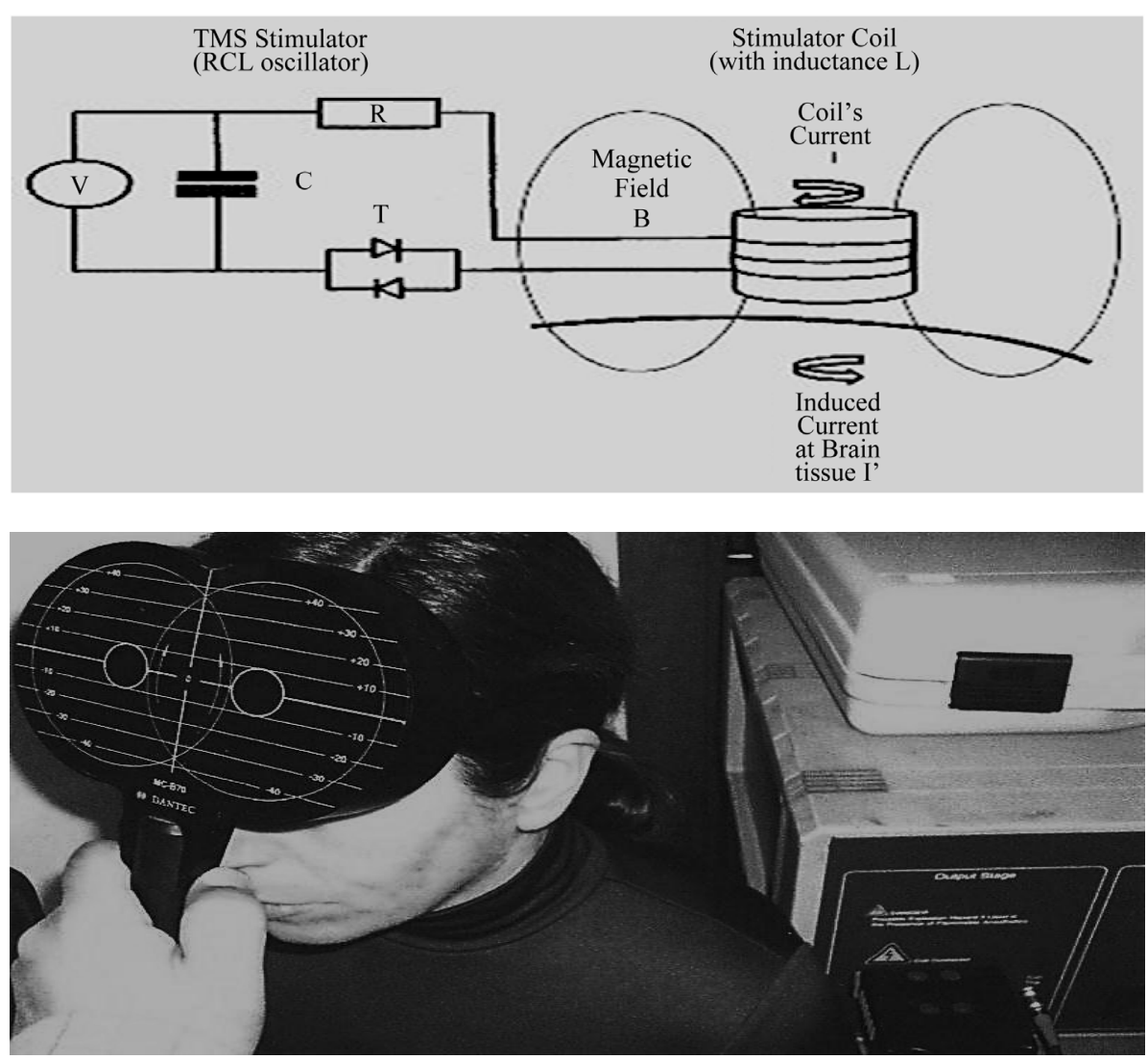

Figure 2. Top: Basic Transcranial Magnetic Stimulation (TMS) power electronics circuit. The TMS electronics circuit is a RCL oscillator, and consists of a Capacitor (with Capacitance C), a Thyristor switch (T), a stimulating coil (with Inductance L) and a Resistance R (in the coil, cables). The Capacitor is first charged to some Kilovolt, and then discharged through the Coil, by gating the Thyristor into a conducting state. The resulting damped sinusoidal current pulse I has a peak value of 5 - 10 Kiloampere. Down: Magnetic Stimulator and "figure-of-eight" inductive stimulating coil, positioned over subject's medial Prefrontal Cortex (mPFC).

depression and relative underactivity of the left DLPFC [51-58]. The most clinically effective rTMS parameters and the optimal site for stimulation in Stress related Disorders are not currently known. The target area of cortical stimulation for any TMS study should be determined according to the theorized underlying neurophysiology and the treatment goal. Procedures can be implemented to monitor for early detection of seizures and/or minimize risk of seizures - electroencephalography and/or electromyography monitoring can be used to check for signs of spread of excitation and after-discharges [59, $60]$.

\subsection{Heart's Innervation and Conducting System [61] (Figure 3)}

The extracardiac nervous part comprises nerve conductors, connecting heart's nervous system with central nervous system, and with nervous structures of other organs. The intracardiac nervous system integrates nerve plexuses and endings. Cardiac innervation has sources the branch of the sympathetic trunk and the branches of the cervical and thoracic parts of the vagus nerve. Three cardiac nerves - superior, middle and inferior-arise on the each side from the ganglia and interganglionic connections of the sympathetic trunk. The superior cervical cardiac nerve originates from the superior cervical plexus, and it is an isolated trunk, composed of branches joined into a single nerve in the lower part of the neck. The middle cervical cardiac nerve arises from the middle cervical ganglion. The inferior cervical cardiac nerve arises from the inferior cervical or stellate ganglion, it is represented by, at least, one trunk, and, frequently, it communicates with the branches of the vagus nerve. The vagus nerves and their branches (the superior laryngeal and the recurrent laryngeal nerves) give rise to the superior and inferior cardiac branches. The superior cardiac branches originate from the trunk of the vagus nerve immediately below the ganglion nodosum and from the superior laryngeal nerve. The highest branch is called the depressor nerve (Zion's nerve). The inferior cardiac 

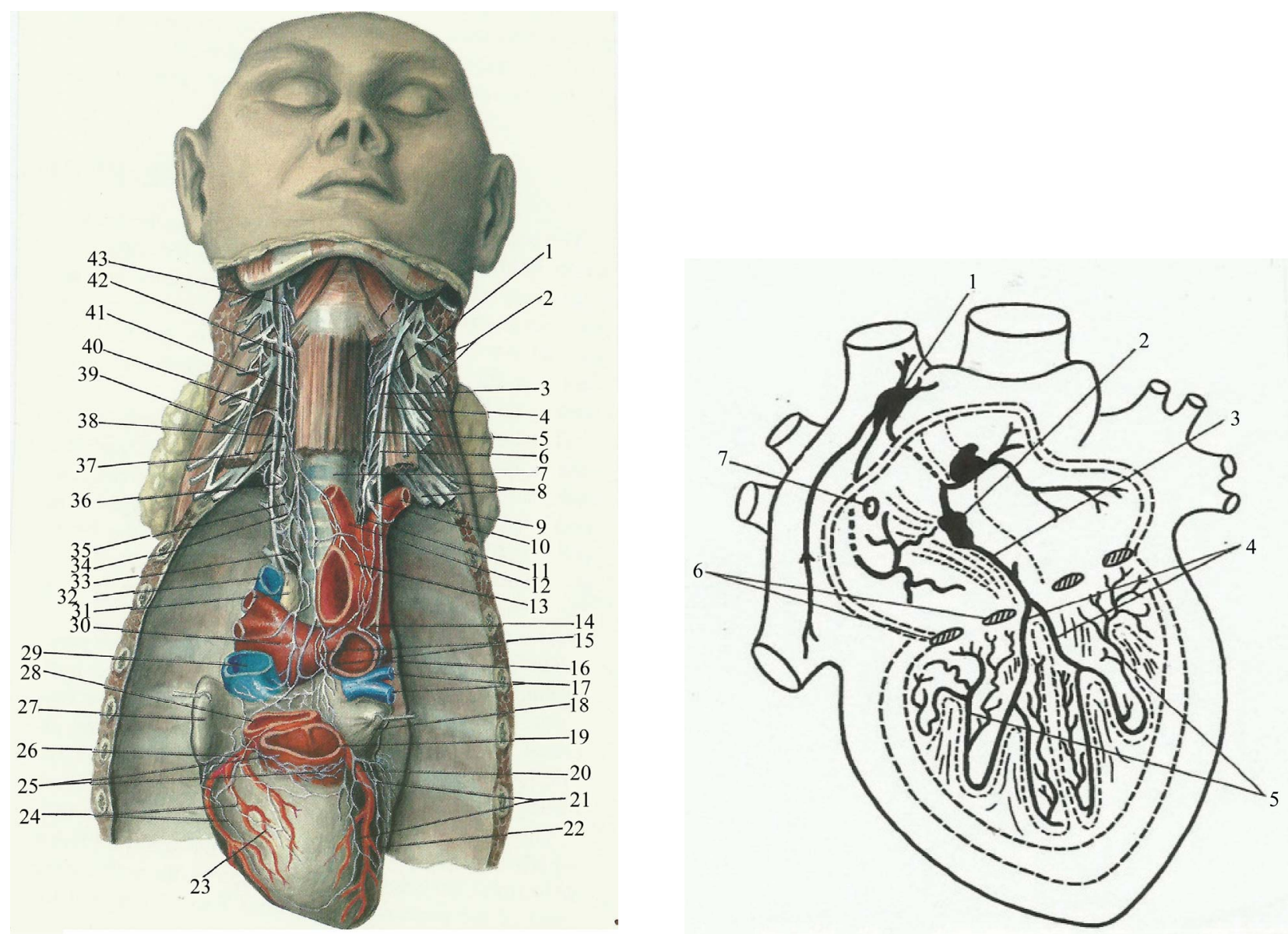

Figure 3. Functional anatomy of heart's innervation and conducting system. Left: Nerves of heart. (1) Left superior cervical cardiac nerve; (2) Left cervical plexus; (3) Left sympathetic trunk; (4) Left vagus nerve; (5) Left phrenic nerve; (6) Anterior scalene muscle; (7) Trachea; (8) Left brachial plexus; (9) Left subclavian artery; (10) Left inferior cervical cardiac nerve; (11) Brachiocephalic trunk; (12) Left common carotid artery; (13) Arch of aorta; (14) Left recurrent laryngeal nerve; (15) Anterior atrial plexus; (16) Left pulmonary artery; (17) Pulmonary veins; (18) Left atrial auricle; (19) Pulmonary trunk; (20) Left coronary artery; (21) Left anterior plexus; (22) Left ventricle; (23) Right ventric1e; (24) Right anterior plexus; (25) Ganglion field in lhe region of conus arteriosus; (26) Right coronarv artery; (27) Right atrial auricle; (28) Aorta; (29) Superior vena cava; (30) Right pulmonary artery; (31) Lymph node; (32) Azygos vein; (33) Right inferior cervical cardiac nerve; (34) Right recurrent laryngeal nerve; (35) Right inferior cardiac branch; (36) First thoracic ganglion; (37) Inferior cervical ganglion of right sympathetic trunk; (38) Right superior cardiac branch; (39) Right phrenic nerve; (40) Right vagus nerve; (41) Right sympathetic trunk; (42) Superior cervical cardiac nerve; (43) Superior laryngeal nerv (adapted from V. Vorobiev). Right: Conducting system of heart. (1) Sinoatrial node; (2) Atrioventricular node; (3) Bundle of His; (4) Branch of bundle of His; (5) Network of Purkinje's fibers; (6) Coronary sinus; (7) Heart valve (adapted from F. Volynskii) (in Atlas of Thoracic Surgery, by Boris V. Petrovsky, Mosby Company, Toronto, 1979).

branches form from the trunk of the vagus nerve and from the recurrent laryngeal nerve in the lower part of the neck and in the mediastinum. The cardiac nerves and branches arising from the sympathetic and vagus nerves, repeatedly intertwining, form nerve plexuses along the length of the large vessels. The conducting system of the heart is composed of special muscle fibers which can transmit impulses from the nerve apparatus to all groups of the heart muscles, and are syncytially connected with one another, forming ganglia and bundles. The sinoatrial system consists of the Keith-Flack sinus node - situated in the wall of the right atrium under the epicardium between the right auricula and the superior vena cava — and two inconstant bundles (Wenckebach's and Schenberg's bundles). The atrioventricular system consists of the Aschoff-Tawara node and the atrioventricular bundle of His and its two branches. The Aschoff-Tawara atrioventricular node is situated in the posteroinferior part of the interatrial septum above the orifice of the coronary sinus. Lower down, the node is continuous with the bundle of His, which penetrates the membranous part of the interventricular septum and divides into the right and left branches (limbs). Both branches descend to the apex of the heart along the septal surfaces, dividing into terminal branches, Purkinje's fibers, which spread in the fibers of the myocardium. The sinoatrial and atrioventricular parts 
of the conducting system are connected with one another by nerve pathways, which accomplish the complicated and versatile contact of the conducting system with all the nerve apparatuses of the heart. The automatic rhythm of the cardiac contraction originates in the sinoatrial Keith-Flack node (pacemaker), and impulses from it spread, in the musculature of the atria, to the AschoffTawara node, and, from there, along the bundle of His, to the musclature of the ventricles. Within a functional perspective, at the sinoatrial Keith-Flack node it converges the antagonic modulatory parasympathetic (vagal) and the sympathetic nervous (ANS) tonus, translated, namely, into Heart Rate Variability (HRV).

\section{PRELIMINAR INVESTIGATION ON BRAIN PROCESSING OF ACUTE STRESSOR-EVOKED CARDIOVASCULAR REACTIVITY, USING REPETITIVE TRANSCRANIAL MAGNETIC STIMULATION (rTMS) OVER THE MEDIAL PREFRONTAL CORTEX (mPFC, BA 10)}

\subsection{Methods}

A 52 years old male and a 40 years old female with previ- ous increased Low Frequency (LF)/High Frequency (HF) Heart Rate Variability (HRV) ratios (respectively, 4.209/ 3.028) without decompensated cardiorespiratory symptomatology, gave informed consent, and ethico-legal issues have been observed. Electroencephalographic (EEG) monitoring has been performed for safety purposes. Immediately after administration, over the $\mathrm{mPFC}$, of 15 pulses of rTMS, during 60 second, with an inductive electrical current, at the stimulating coil, of 85.9 Ampère per $\mu$ second and 66 Ampère per $\mu$ second, respectively, for male and female subjects (a "figure-eight" coil and magnetic stimulator MagLite, Dantec/Medtronic, have been used), HRV spectrum analysis (cStress software) has been performed (during 5 minutes, in supine position).

\subsection{Results (Table 1)}

In both subjects, LF power, HF power and LF/HF ratio results, before and after rTMS administration, pointed towards sympathetic attenuation and parasympathetic augmentation (respectively, in male/female subject: decreased LF power- $65.1 \mathrm{nu} / 69.3 \mathrm{nu}$, before rTMS; 56.1 nu/41.6 nu, after rTMS; increased HF power-15.5 nu/22.9 nu, before rTMS; 30.9 nu/45.5 nu, after rTMS).

Table 1. Heart Rate Variability (HRV) spectrum analysis before (left) and after (right) administration of rTMS. High Frequencies (HF) Power increased and Low Frequencies (LF) Power decreased, contributing for decreased LF/HF ratio in both subjects (sympathetic attenuation and parasympathetic activation).

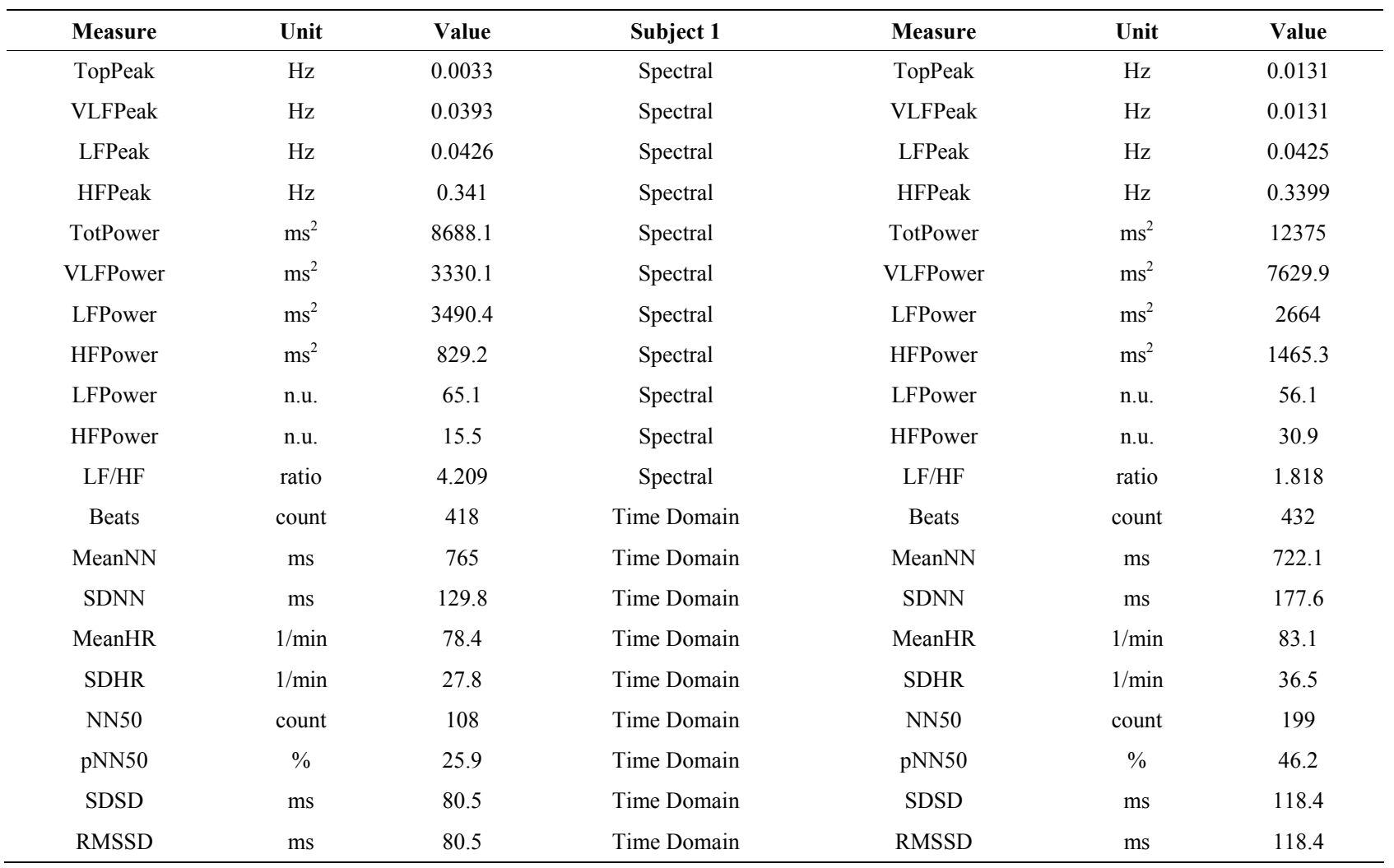


Continued

\begin{tabular}{|c|c|c|c|c|c|c|}
\hline Measure & Unit & Value & Subject 1 & Measure & Unit & Value \\
\hline TopPeak & $\mathrm{Hz}$ & 0.0033 & Spectral & TopPeak & $\mathrm{Hz}$ & 0.0066 \\
\hline VLFPeak & $\mathrm{Hz}$ & 0.0033 & Spectral & VLFPeak & $\mathrm{Hz}$ & 0.0066 \\
\hline LFPeak & $\mathrm{Hz}$ & 0.0498 & Spectral & LFPeak & $\mathrm{Hz}$ & 0.063 \\
\hline HFPeak & $\mathrm{Hz}$ & 0.2952 & Spectral & HFPeak & $\mathrm{Hz}$ & 0.1758 \\
\hline TotPower & $\mathrm{ms}^{2}$ & 188.8 & Spectral & TotPower & $\mathrm{ms}^{2}$ & 1158.2 \\
\hline VLFPower & $\mathrm{ms}^{2}$ & 154.4 & Spectral & VLFPower & $\mathrm{ms}^{2}$ & 346.6 \\
\hline LFPower & $\mathrm{ms}^{2}$ & 23.8 & Spectral & LFPower & $\mathrm{ms}^{2}$ & 337.3 \\
\hline HFPower & $\mathrm{ms}^{2}$ & 7.8 & Spectral & HFPower & $\mathrm{ms}^{2}$ & 369.1 \\
\hline LFPower & n.u. & 69.3 & Spectral & LFPower & n.u. & 41.6 \\
\hline HFPower & n.u. & 22.9 & Spectral & HFPower & n.u. & 45.5 \\
\hline $\mathrm{LF} / \mathrm{HF}$ & ratio & 3.028 & Spectral & $\mathrm{LF} / \mathrm{HF}$ & ratio & 0.914 \\
\hline Beats & count & 409 & Time Domain & Beats & count & 386 \\
\hline MeanNN & $\mathrm{ms}$ & 682.1 & Time Domain & MeanNN & $\mathrm{ms}$ & 754.1 \\
\hline SDNN & $\mathrm{ms}$ & 19.9 & Time Domain & SDNN & $\mathrm{ms}$ & 43.6 \\
\hline MeanHR & $1 / \min$ & 88 & Time Domain & MeanHR & $1 / \min$ & 79.6 \\
\hline SDHR & $1 / \min$ & 2.6 & Time Domain & SDHR & $1 / \mathrm{min}$ & 3.8 \\
\hline NN50 & count & 0 & Time Domain & NN50 & count & 9 \\
\hline pNN50 & $\%$ & 0 & Time Domain & pNN50 & $\%$ & 2.3 \\
\hline SDSD & $\mathrm{ms}$ & 6.6 & Time Domain & SDSD & $\mathrm{ms}$ & 47.4 \\
\hline RMSSD & $\mathrm{ms}$ & 6.6 & Time Domain & RMSSD & $\mathrm{ms}$ & 47.4 \\
\hline
\end{tabular}

\subsection{Discussion}

The actual study results on the neural correlates of stressor-evoked cardiovascular reactivity, using TMS, altought limited, are consistent with Lane et al. correlational study [32]. Those results suggest that transient disruption/virtual lesion of brain circuitries involved in stress information processing and stressor-evoked cardiovascular reactivity may allow individual stratification concerning risk for the development of Coronary Heart Disease (CHD). It detects persons more prone to develop CHD, particularly those which brain circuities involved in stressor-evoked cardiovascular reactivity may be already affected by subclinical cerebrovascular lesions (e.g., "vascular depression"). The most clinically effective rTMS parameters and the optimal site for stimulation in Stress related Disorders are not currently known. The target area of cortical stimulation for any TMS study should be determined according to the theorized underlying neurophysiology and the treatment goal.

\section{CONCLUSIONS}

In this preliminary investigation, the existence of a link between "mind" and heart's function has been put in evidence, through a reversible "virtual" lesion, of brain systems, involved in cardiovascular control, caused by Transcranial Magnetic Stimulation (TMS). Repetitive
TMS over medial Prefrontal Cortex (pmPFC) decreased brain function involved in stressor-evoked cardiovascular reactivity, and suggested the importance of TMS in the management of stress-related cardiovascular disorders. More controlled research is needed for an integrated understanding of the pathogeny of essential hypertension, partially explained through kindling/Long Term Potentiation (LTP) mechanisms of brain neural networks involved in stressor-evoked cardiovascular reactivity, which may be quenched through the administration of repetitive Transcranial Magnetic Stimulation (rTMS).

\section{ACKNOWLEDGEMENTS}

The corresponding author acknowledges the technical support and comments of Professors Peter Gianaros (from the Center for the Neural Basis of Cognition, University of Pittsburgh School of Medicine, USA), Theresa Pape (from the Department of Veterans Affairs Research Service, Northwestern University, Chicago, USA) and Saul Neves de Jesus (from the Department of Psychology of the University of Algarve, Faro, Portugal).

\section{REFERENCES}

[1] Barbas, H., Saha, S., Rempel-Clower, N. and Ghashghaei, T. (2003) Serial pathways from primate prefrontal cortex to autonomic areas may influence emotional expression. BMC Neuroscience, 4, 25. 
http://dx.doi.org/10.1186/1471-2202-4-25

[2] Critchley, H.D. (2005) Neural mechanisms of autonomic, affective, and cognitive integration. Journal of Comparative Neurology, 493, 154-166.

http://dx.doi.org/10.1002/cne.20749

[3] Vogt, B.A. and Laureys, S. (2005) Posterior cingulate, precuneal and retrosplenial cortices: Cytology and components of the neural network correlates of consciousness. Progress in Brain Research, 150, 205-217. http://dx.doi.org/10.1016/S0079-6123(05)50015-3

[4] Vogt, B.A. and Pandya, D.N. (1987) Cingulate cortex of the rhesus monkey: II cortical afferents. Journal of Comparative Neurology, 262, 271-289.

http://dx.doi.org/10.1002/cne. 902620208

[5] Lane, R.D., Reiman, E.M., Axelrod, B., Yun, L.S., Holmes, A. and Schwartz, G.E. (1998) Neural correlates of levels of emotional awareness. Evidence of an interaction between emotion and attention in the anterior cingulate cortex. Journal of Cognitive Neuroscience, 10, 525535. http://dx.doi.org/10.1162/089892998562924

[6] Ochsner, K.N. and Cross, J.J. (2005) The cognitive controI of emotion. Trends in Cognitive Sciences, 9, 242-249. http://dx.doi.org/10.1016/j.tics.2005.03.010

[7] Critchley, H.D., Melmed, R.N., Featherstone, E., Mathias, C.J. and Dolan, R.J. (2002) Volitional control of autonomic arousal: A functetional magnetic resonance study. NeuroImage, 16, 909-919. http://dx.doi.org/10.1006/nimg.2002.1147

[8] Gianaros, P.J., Derbyshire, S.W., May, J.C., Siegle, G.J., Gamalo, M.A. and Jennings, J.R. (2005) Anterior cingulate activity correlates with blood pressure during stress. Psychophysiology, 42, 627-635. http://dx.doi.org/10.1111/j.1469-8986.2005.00366.x

[9] Augustine, J.R. (1996) Circuitry and functional aspects of the insular lobe in primates including humans. Brain Research Reviews, 22, 229-244. http://dx.doi.org/10.1016/S0165-0173(96)00011-2

[10] Verberne, A.J. and Owens, N.C. (1998) Cortical modulation of the cardiovascular system. Progress in Neurobiology, 54, 149-168.

http://dx.doi.org/10.1016/S0301-0082(97)00056-7

[11] Craig, A.D. (2003) Interoception: The sense of the physiological condition of the body. Current Opinion in Neurobiology, 13, 500-505. http://dx.doi.org/10.1016/S0959-4388(03)00090-4

[12] Critchley, H.D., Corfield, D.R., Chandler, M.P., Mathias, C.J. and Dolan, R.J. (2000) Cerebral correlates of autonomic cardiovascular arousal: A functional neuroimaging investigation in humans. Journal of Physiology, 523, 259-270.

http://dx.doi.org/10.1111/j.1469-7793.2000.t01-1-00259.x

[13] Gianaros, P.J. (2008) Brain-bodv pathways to cardiovascular disease risk. Herbert Weiner Early Career Award Lecture, 66th Annual Meeting of the American Psychosomatic Society, Baltimore.

[14] Gianaros, P.J., Horenstein, J.A., Cohen, S., Matthews, K.A., Brown, S.M., Flory, J.D., et al. (2007) Perigenual anterior cingulate morphology covaries with perceived social standing. Social Cognitive and Affective Neuroscience, 2, 161-173. http://dx.doi.org/10.1093/scan/nsm013

[15] Gianaros, P.J., Horenstein, J.A., Hariri, A.K., Sheu, L.K., Manuck, S.B., Matthews, K.A., et al. (2008) Potential neural embedding of parental social standing. Social Cognitive and Affective Neuroscience, 3, 91-96.

http://dx.doi.org/10.1093/scan/nsn003

[16] Gianaros, P.J., Jennings, J.K., Sheu, L.K., Derbyshire, S.W. and Matthews, K.A. (2007) Heightened functional neural activation to psychological stress covaries with exaggerated blood pressure reactivity. Hypertension, 49, 134-140. http://dx.doi.org/10.1161/01.HYP.0000250984.14992.64

[17] Gianaros, P.J., Jennings, J.K., Sheu, L.K., Greer, P.J., Kuller, L.H. and Matthews, K.A. (2007) Prospective reports of chronic life stress predict decreased grey matter volume in the hippocampus. NeuroImage, 35, 795-803. http://dx.doi.org/10.1016/j.neuroimage.2006.10.045

[18] Gianaros, P.J., Sheu, L.K., Matthews, K.A., Jennings, J.K., Manuck, S.B. and Hariri, A.R. (2008) Individual differences in stressor-evoked blood pressure reactivity vary with activation, volume, and functional connectivity of the amygdala. Journal of Neuroscience, 28, 990-999. http://dx.doi.org/10.1523/JNEUROSCI.3606-07.2008

[19] Gianaros, P.J., Van der Veen, F.M. and Jennings, J.K. (2004) Regional cerebral blood flow correlates with heart period and highfrequency heart period variability during working-memory tasks: Implications for the cortical and subcortical regulation of cardiac autonomic activity. Psychophysiology, 41, 521-530. http://dx.doi.org/10.1111/1469-8986.2004.00179.x

[20] Davis, M. and Whalen, P.J. (2001) The amygdala: Vigilance and emotion. Molecular Psychiatry, 6, 13-34. http://dx.doi.org/10.1038/sj.mp.4000812

[21] LeDoux, J. (2003) The emotional brain, fear, and the amygdala. Cellular and Molecular Neurobiology, 23, 727-738. http://dx.doi.org/10.1023/A:1025048802629

[22] Sah, P., Faber, E.S., Lopez De Armentia, M. and Power, J. (2003) The amygdaloid complex: Anatomy and physiology. Physiological Reviews, 83, 803-834.

[23] Zald, D.H. (2003) The human amygdala and the emotional evaluation of sensory stimuli. Brain research. Brain Research Reviews, 41, 88-123. http://dx.doi.org/10.1016/S0165-0173(02)00248-5

[24] Amaral, D.G. and Price, J.L. (1984) Amygdalo-cortícal projections in the monkey (Macaca fascicularis). Journal of Comparative Neurology, 230, 465-496. http://dx.doi.org/10.1002/cne.902300402

[25] McDonald, A.J. (1998) Cortical pathways to the mammahan amygdala. Progress in Neurobiology, 55, 257-332. http://dx.doi.org/10.1016/S0301-0082(98)00003-3

[26] Price, J.L. (2003) Comparative aspects of amygdala connectivity. Annals of the New York Academy of Sciences, 985, 50-58. http://dx.doi.org/10.1111/j.1749-6632.2003.tb07070.x

[27] Berntson, G.G., Sarter, M. and Cacioppo, J.T. (1998) Anxiety and cardiovascular reactivity: The basal forebrain cholinergic link. Behavioural Brain Research, 94, 
225-248. http://dx.doi.org/10.1016/S0166-4328(98)00041-2

[28] Dampney, R.A. (1994) Functional organization of central pathways regulating the cardiovascular system. Physiological Reviews, 74, 323-364.

[29] Saha, S. (2005) Role of the central nucleus of the amygdala in the control of blood pressure: Descending pathways to medullary cardiovascular nuclei. Clinical and Experimental Pharmacology and Physiology, 32, 450456. http://dx.doi.org/10.1111/j.1440-1681.2005.04210.x

[30] Saper, C.B. (2002) The central autonomic nervous system: Conscious visceral perception and autonomic pattern generation. Annual Review of Neuroscience, 25, 433-469. http://dx.doi.org/10.1146/annurev.neuro.25.032502.11131 1

[31] O’Connor, M.F., GündeI, H., McRae, K. and Lane, R.O. (2007) Baseline vagal tone predicts BOLD response during elicitation of grief. Neuropsychopharmacology, 32, 2184-2189. http://dx.doi.org/10.1038/sj.npp.1301342

[32] Lane, R.D., Reiman, E.M., Ahern, G.L. and Thayer, J.F. (2001) Activity in the medial prefrontal cortex correlates with vagal component of heart rate variability. Brain and Cognition, 47, 97-100.

[33] Barker, A.T., Jalinous, R. and Freeston, I.L. (1985) Noninvasive magnetic stimulation of human motor cortex. Lancet, 1, 1106-1107. http://dx.doi.org/10.1016/S0140-6736(85)92413-4

[34] Wilson, S.A., Thickbroom, G.W. and Mastaglia, F.L. (1993) Transcranial magnetic stimulation mapping of the motor cortex in normal subjects. Journal of the Neurological Sciences, 118, 134-144. http://dx.doi.org/10.1016/0022-510X(93)90102-5

[35] Wassermann, E.M., McShane, L.M., Hallett, M. and Cohen, L.G. (1992) Noninvasive mapping of muscle representations in human motor cortex. Electroencephalography and Clinical Neurophysiology, 85, 1-8. http://dx.doi.org/10.1016/0168-5597(92)90094-R

[36] Rossini, P.M. and Rossi, S. (1998) Clinical applications of motor evoked potentials. Electroencephalography and Clinical Neurophysiology, 106, 180-194. http://dx.doi.org/10.1016/S0013-4694(97)00097-7

[37] Classen, J., Liepert, J., Wise, S.P., Hallett, M. and Cohen, L.G. (1998) Rapid plasticity of human cortical movement representation induced by practice. Journal of Neurophysiology, 79, 1117-1123.

[38] Pascual-Leone, A., Walsh, V. and Rothwell, J.C. (2000) Transcranial magnetic stimulation in cognitive neuroscience-virtual lesion, chronometry, and functional connectivity. Current Opinion in Neurobiology, 10, 232-237. http://dx.doi.org/10.1016/S0959-4388(00)00081-7

[39] Siebner, H.R. and Rothwell, J.C. (2002) Transcranial magnetic stimulation: New insights into representational cortical plasticity. Experimental Brain Research, 148, 116. http://dx.doi.org/10.1007/s00221-002-1234-2

[40] Wassermann, E.M. (1998) Risk and safety of repetitive transcranial magnetic stimulation: Report and suggested guidelines from the International Workshop on the Safety of Repetitive Transcranial Magnetic Stimulation. Elec- troencephalography and Clinical Neurophysiology, 108, 1-16. http://dx.doi.org/10.1016/S0168-5597(97)00096-8

[41] Lemon, R. (2002) Basic physiology of transcranial magnetic stimulaiton. In: Pascual-Leone, A., Davey, N.J., Rothwell, J., Wasserman, E.M. and Puri, B.K., Eds., Handbook of Transcranial Magnetic Stimulation. Arnold, London, 61-77.

[42] Feinsod, M., Kreinin, B., Chistyakov, A. and Klein, E. (1998) Preliminary evidence for a beneficial effect of low-frequency, repetitive transcranial magnetic stimulation in patients with major depression and schizophrenia. Depression and Anxiety, 7, 65-68.

http://dx.doi.org/10.1002/(SICI)1520-6394(1998)7:2<65:: AID-DA2>3.0.CO;2-4

[43] Di Lazzaro, V., Oliviero, A., Mazzone, P., et al. (2002) Short-term reduction of intracortical inhibition in the human motor cortex induced by repetitive transcranial magnetic stimulation. Experimental Brain Research, 147, 108-113. http://dx.doi.org/10.1007/s00221-002-1223-5

[44] Rossini, P.M., Barker, A.T., Berardelli, A., et al. (1994) Noninvasive electrical and magnetic stimulation of the brain, spinal cord and roots: Basic principles and procedures for routine clinical application. Report of an IFCN committee. Electroencephalography and Clinical Neurophysiology, 91, 79-92.

http://dx.doi.org/10.1016/0013-4694(94)90029-9

[45] Wassermann, E.M. (2002) Variation in the response to transcranial magnetic brain stimulation in the general population. Clinical Neurophysiology, 113, 1165-1171. http://dx.doi.org/10.1016/S1388-2457(02)00144-X

[46] Muellbacher, W., Ziemann, U., Boroojerdi, B. and Hallett, M. (2000) Effects of low-frequency transcranial magnetic stimulation on motor cortex excitability and basic motor behavior. Clinical Neurophysiology, 111, 1002-1007. http://dx.doi.org/10.1016/S1388-2457(00)00284-4

[47] Chen, R., Classen, J., Gerloff, C., et al. (1997) Depression of motor cortex excitability by low-frequency transcranial magnetic stimulation. Neurology, 48, 1398-1403. http://dx.doi.org/10.1212/WNL.48.5.1398

[48] Berardelli, A., Inghilleri, M., Rothwell, J.C., et al. (1998) Facilitation of muscle evoked responses after repetitive cortical stimulation in man. Experimental Brain Research, 122, 79-84. http://dx.doi.org/10.1007/s002210050493

[49] Pascual-Leone, A., Valls-Sole, J., Wassermann, E.M. and Hallet, M. (1998) Responses to rapid-rate transcranial magnetic stimulation of the human motor cortex. Brain, 117, 847-858. http://dx.doi.org/10.1093/brain/117.4.847

[50] Peinemann, A., Reimer, B., Loer, C., et al. (2004) Long-lasting increase in corticospinal excitability after 1800 pulses of subthreshold $5 \mathrm{~Hz}$ repetitive TMS to the primary motor cortex. Clinical Neurophysiology, 115, 1519-1526.http://dx.doi.org/10.1016/j.clinph.2004.02.005

[51] Karp, B.I., Wassermann, E.M., Porter, S. and Hallett, M. (1997) Transcranial magnetic stimulation acutely decreases motor tics. Neurology, 48, A397.

[52] Siebner, H.R., Auer, C., Ceballos Baumann, A.O., Conrad, B. and Pascual-Leone, A. (1997) Low-frequency repetitive magnetic stimulation of the motor cortex reduces increased writing pressure in writer's cramp. Electroe- 
ncephalography and Clinical Neurophysiology, 103, 10.

[53] Pascual-Leone, A., Valls-Sole, J., Brasil-Neto, J.P., Cammarota, A., Grafman, J. and Hallet, M. (1994) Akinesia in Parkinson's disease. II. Effects of subthreshold repetitive transcranial motor cortex stimulation. Neurology, 44, 892-898. http://dx.doi.org/10.1212/WNL.44.5.892

[54] Lefaucheur, J.P., Drouot, X., Von Raison, F., MenardLefaucheur, I., Cesaro, P. and Nguyen, J.P. (2004) Improvement of motor performance and modulation of cortical excitability by repetitive transcranial magnetic stimulation of the motor cortex in Parkinson's disease. Clinical Neurophysiology, 115, 2530-2541. http://dx.doi.org/10.1016/j.clinph.2004.05.025

[55] Siebner, H.R., Mentschel, C., Auer, C. and Conrad, B. (1999) Repetitive transcranial magnetic stimulation has a beneficial effect on bradykinesia in Parkinson's disease. Neuroreport, 10, 589-594. http://dx.doi.org/10.1097/00001756-199902250-00027

[56] Siebner, H.R., Rossmeier, C., Mentschel, C., Peinemann, A. and Conrad, B. (2000) Short-term motor improvement after sub-threshold $5-\mathrm{Hz}$ repetitive transcranial magnetic stimulation of the primary motor hand area in Parkinson's disease. Journal of the Neurological Sciences, 178, 91-94. http://dx.doi.org/10.1016/S0022-510X(00)00370-1
[57] Khedr, E.M., Ahmed, M.A., Fathy, N. and Rothwell, J.C. (2005) Therapeutic trial of repetitive transcranial magnetic stimulation after acute ischemic stroke. Neurology, 65, 466-468. http://dx.doi.org/10.1212/01.wnl.0000173067.84247.36

[58] George, M.S., Wassermann, E.M., Williams, W.A., et al. (1995) Daily repetitive transcranial magnetic stimulation (rTMS) improves mood in depression. Neuroreport, 6, 1853-1856.

http://dx.doi.org/10.1097/00001756-199510020-00008

[59] Burt, T., Lisanby, S.H. and Sackeim, H.A. (2002) Neuropsychiatric applications of transcranial magnetic stimulation: A meta analysis. The International Journal of Neuropsychopharmacology, 5, 73-103. http://dx.doi.org/10.1017/S1461145702002791

[60] Wassermann, E.M. (2002) Safety and side-effects of transcranial magnetic stimulation and repetitive transcranial magnetic stimulation. In: Pascual-Leone, A., Davey, N.J., Rothwell, J., Wasserman, E.M. and Puri, B.K., Eds., Handbook of Transcranial Magnetic Stimulation. Arnold, New York, 39-49.

[61] Petrovsky, B.V. (1979) Atlas of thoracic surgery. Mosby Company, Toronto. 